\title{
La universalidad de monseñor Romero
}

El año 2015 quedará grabado en la historia y en la memoria del pueblo salvadoreño. Para los seguidores de Óscar Arnulfo Romero y Galdámez, el obispo mártir del más pequeño de los países del continente, los treinta y cinco años que transcurrieron desde su magnicidio, el 24 de marzo de 1980, fueron una eternidad. Cuentan testigos que aquella noche, desde la plaza donde está el monumento al Divino Salvador del Mundo, hacia arriba, al oeste de la ciudad, reventaron cohetes festivos porque habían asesinado a la voz más autorizada del país y la más querida por los pobres que se sentían representados en ella. Esa era la zona donde se situaban las residencias de las familias salvadoreñas más adineradas e influyentes que, por el contrario, se sentían contrariadas por la voz del profeta.

Esa misma plaza del patrono de El Salvador, el 23 de mayo de este año 2015, fue insuficiente para albergar a decenas de miles de personas que se dieron cita para celebrar no la muerte, sino la vida de su obispo que fue declarado oficialmente Beato por la Iglesia Católica. En su proclamación se le reconoció como "obispo y mártir, pastor según el corazón de Cristo, evangelizador y padre de los pobres, testigo heroico del Reino de Dios, Reino de justicia, fraternidad y paz". Aquella mañana, cada referencia a monseñor Romero fue celebrada con aplausos y vítores por la gente llegada hasta de los últimos rincones del país y de más de 57 países, según el registro que llevaron los organizadores. Fuentes de la Iglesia calcularon la multitud en más de 300000 personas. Agencias internacionales hablaron de al menos unas 250 000. Es difícil dar un dato numérico exacto, pero lo que nadie podrá negar es la manifestación masiva de cariño, admiración y agradecimiento a quien dio su vida por ponerse del lado de los que más sufren. Más allá de las fronteras de El Salvador, miles de personas siguieron la ceremonia que fue transmitirá en vivo a través de la internet.

\section{Reconocimiento internacional}

Muchas veces se ha repetido que Romero es el salvadoreño más universal. Entender esta afirmación solo en el sentido de que es el salvadoreño más conocido en el mundo no explica completamente el carácter universal de su legado. Antes de que en su misma patria, por lo menos de manera oficial y, por supuesto, antes de que lo hiciera la jerarquía de su Iglesia, monsenor Romero fue reconocido a nivel internacional.

Organizaciones de base, religiosas, políticas y de la sociedad civil en muchos lugares del mundo retomaron la figura y el testimonio de Romero como referencia de su ideario. Su vida ha sido motivo de inspiración para 
El 24 de marzo de todos los años se ha consagrado tanto a las víctimas como a la memoria del obispo de quien se dice que fue "defensor de los débiles y hecho débil hasta la muerte por quienes abusan de los pobres". cantautores, poetas, pintores y teólogos. Muchas plazas llevan su nombre y hay innumerables Comités de Solidaridad "Monseñor Romero" dispersos por todo el mundo haciendo su trabajo a favor de los pobres.

En América Latina, casi inmediatamente después de su muerte, se comenzó a referirse al obispo como "San Romero de América", titulo con que lo bautizó el obispo de Mato Grosso, Brasil, don Pedro Casaldáliga, en un bello poema inspirado en su legado. El reconocimiento a monseñor Romero trascendió también las fronteras religiosas. La Iglesia anglicana lo incluyó en su santoral y lo mismo hizo la Iglesia luterana. También fue reconocido como uno de los diez mártires del siglo XX representados en las estaturas de la abadía de Westminster de Londres. El parlamento británico lo nominó al Premio Nobel de la Paz en 1979 y por lo menos cinco universidades de Estados Unidos, Centroamérica y Europa le reconocieron el compromiso con su pueblo a través de doctorados honoris causa, además, de los diversos premios que recibió fuera de su tierra. Hasta un asteroide fue rebautizado con su nombre.

Monseñor Romero es el único, entre todos los beatos y santos y santas católicos, que tiene un día especial en las conmemoraciones internacionales que promueven las Naciones Unidas. El 24 de marzo de todos los años se ha consagrado tanto a las víctimas como a la memoria del obispo de quien se dice que fue "defensor de los débiles y hecho débil hasta la muerte por quienes abusan de los pobres". En su resolución, la ONU lo recuerda también como ejemplar por su profundo humanismo y servicio a la humanidad, su defensa de los derechos humanos (incluyendo la denuncia de la violación de estos), la protección de la vida, la defensa de la dignidad humana, los llamados al diálogo y la oposición a toda forma de violencia.

Todos los ejemplos anteriores confirman el legado universal de monseñor Romero. Pero para que el obispo declarado "mártir por odio a la fe" se convirtiera en símbolo de referencia en muchas latitudes, ha sido indispensable no descontextualizarlo ni en el tiempo ni en el lugar donde ejerció su misión.

\section{Profeta en su tierra}

De Romero hay que decir que en su propio país fue querido y rechazado. Muy querido por los que luchaban por la justicia, especialmente por quienes sufrían la injusticia de la pobreza, de la persecución política, del terror desatado por quienes no querían que nada cambiara. Por el contrario, fue rechazado por quienes ejercían la represión, por los que no querían renunciar a sus privilegios, por quienes veían - en cualquier muestra de inconformidad con lo que pasaba- una alineación con el comunismo internacional.

Sin lugar a dudas, el pueblo que sentía en él a un defensor suyo, desde antes de su martirio no dudó en darle un lugar especial en su corazón y volverlo su guía espiritual. La beatificación del arzobispo el 23 de mayo fue tan 
celebrada y produjo tanto regocijo en gran parte del pueblo porque su reconocimiento oficial era también el reconocimiento de todos los que lucharon y murieron por la verdad, de los que se pusieron de parte de la justicia, de todas las víctimas inocentes que nunca fueron dignificadas.

\section{Toda expresión de organizaciones $e$ instituciones de iglesia que fuera en la línea de la transformación social las hacía objetivos de la represión.}

El Salvador es el país donde más religiosos fueron asesinados durante el siglo pasado. Al menos 18 sacerdotes, cinco religiosas, decenas de catequistas y miles de salvadoreños que pertenecían a organizaciones eclesiales de base fueron asesinados antes y durante la guerra civil. Toda expresión de organizaciones e instituciones de iglesia que fuera en la línea de la transformación social las hacía objetivos de la represión. Instalaciones de colegios católicos, de universidades como la UCA, de medios de comunicación como la YSAX fueron objetivos de bombas y ametrallamientos. Además, decenas de sacerdotes fueron expulsados. Tampoco se conocen con exactitud las cifras de los muertos durante el conflicto armado. Los cálculos más consensuados hablan de por lo menos 70000 salvadoreños asesinados o desaparecidos, de los cuales la inmensa mayoría era población civil, no beligerante en la guerra.

En este contexto, Romero asumió la protección de la gente que sufría la brutal represión lanzada por un régimen militar y desenmascaró los intentos de este por ocultarlo. Puso su autoridad moral y su cargo para dar voz a los que no tenían ninguna posibilidad de hacerse oír ante ese sufrimiento. Lo hizo aun estando consciente de que eran extremadamente altas las posibilidades de que esa represión se volviera también en su contra. El 9 de marzo de 1980, quince días antes de su asesinato, fue desactivada una bomba colocada en el altar mayor de la Basílica Sagrado Corazón, donde monseñor oficiaría una misa en memoria de Mario Zamora, asesinado días antes por su oposición al régimen. A pesar de esta y otras amenazas, monseñor siguió adelante en defensa de los derechos humanos y denunciando a quienes los violentaban.

Esta opción del pastor lo puso en el corazón del pueblo y de los que querían un cambio en el país, pero también le costó la vida. No fue activista político, como lo quisieron hacer ver (algunos se empeñan todavía en ello), ni alentó la violencia, como argumentaron otros porque él señalaba las injusticias. El país se dividió entre los que le daban la razón y los que lo contrariaban, división a la que no escapó la misma Conferencia Episcopal. Aunque eran muchos más los que vieron en monseñor a Dios mismo que se ponía de su parte, los que se le opusieron tenían el poder del dinero, el poder político y el de las armas. O monseñor se ponía del lado de estos últimos o lo asesinaban. Optó por las mayorías y lo mataron.

\section{Hombre de Dios, hombre de los pobres}

Lo que está en la base de la universalidad del beato Romero es algo muy elemental que, desde el punto de vista dialéctico, es precisamente lo que lo 
hace extraordinario. Que Romero sea el único mártir con una fecha especial en el calendario de las naciones del mundo, que su nombre sea repetido en todas partes, que otras denominaciones religiosas reconozcan su legado, son efectos de algo más primigenio. Tan extraordinaria fue la vida de este obispo nacido en Ciudad Barrios que Ignacio Ellacuría, tan lúcido como crítico, afirmó, en la misa que celebró en la UCA a pocos días del asesinato de

El modelo de santidad de Romero es el de quien lucha contra las estructuras sociales, económicas, políticas y culturales, injustas y contrarias al Reino de Dios. monseñor, que con él "Dios pasó por El Salvador";

y unos meses después escribió que Romero fue "un enviado de Dios para salvar a su pueblo".

Monseñor Romero es grande por haberse puesto del lado de los que más sufren y hacerse uno de ellos. Es una figura de referencia para creyentes y no creyentes porque hizo de los pobres la guía de su trabajo pastoral, pues en ellos reconocía la presencia de Dios. Romero es universal porque se puso del lado de los pequeños, de los sin poder, de los que no tenían voz, y se hizo uno de ellos corriendo la misma suerte que tantos pobres de su tiempo. Para monseñor, acercarse a Dios era preocuparse por el perseguido, por el desnudo, por el pobre, por el torturado, por el prisionero. Lo contrario era alejarse de Dios. Desde su encarnación en la realidad concreta de su pueblo, Romero se hizo universal. Por ello, es imposible entender bien a Romero, si se le separa de la realidad que vivió, de los rostros que defendió y en contra de quiénes los defendió. No se puede separar a monseñor Romero de la historia de El Salvador, porque los que lo asesinaron, queriendo borrarlo, le dieron un lugar especial en ella.

\section{El legado de monseñor Romero}

Monseñor Romero es importante no solo por lo que fue y lo que hizo en un momento específico de la historia de El Salvador. Su ejemplo, como ya vimos, trasciende fronteras geográficas, ideológicas, culturales y religiosas. Pero además, su figura es importante porque la denuncia cristiana contra la injusticia sigue siendo una exigencia de nuestros tiempos.

Concretamente para El Salvador, su reconocimiento como parte del santoral católico puede tener repercusiones importantes. Es cierto que, desde mucho antes de que lo reconociera la Iglesia, monseñor ya era parte del santoral popular. Pero su reconocimiento oficial consolida su figura como el primer salvadoreño presente en la historia universal de la Iglesia y, probablemente, como el único presente en el concierto mundial de las efemérides de las Naciones Unidas. Sin duda en su tierra y en muchos otros lugares, Romero ya es parte del imaginario religioso de muchísima gente.

Desde ahora, monseñor debería ser el referente de la identidad nacional de los salvadoreños, su vida y sus textos tienen que ser conocidos por la niñez en las escuelas. Ya no debería entenderse el papel de la Iglesia sin tener como modelo de pastor a quien fue capaz de hasta ofrendar su vida por la defensa de los más pobres y sufridos en una de las situaciones más difíciles del país. Monseñor también tiene que ser un referente para la democratiza- 
ción, necesaria en muchos países que se autoproclaman democráticos, pues su vida la dedicó a denunciar las desigualdades y las injusticias en una dictadura cruel que negaba los derechos más elementales, sobre todo el primario derecho a la vida.

Pero también, para la Iglesia universal, monseñor es buena noticia. No solo porque fue una persona ejemplar que es asesinada por ponerse del lado de los que sufren, sino también porque es un beato y será un santo venido del mundo sociopolítico en donde él hizo carne el Evangelio. El modelo de santidad de Romero es el de quien lucha contra las estructuras sociales, económicas, políticas y culturales, injustas y contrarias al Reino de Dios. Es el santo que no vive de espaldas a la realidad, sino que está cercano a los más pobres, que muestra una gran sensibilidad ante el dolor de los que sufren y enfrenta la violencia con gran fortaleza. Un santo que llama a la paz desde el arrepentimiento y el perdón. En realidad, Romero es un germen con gran potencialidad para la fraternidad en un mundo tan dividido y herido.

Es muy probable que, especialmente por esta razón - no responder solo al modelo tradicional de santidad, sino también a este nuevo modelo con una dimensión sociopolítica-, Romero ha trascendido las fronteras religiosas y ha sido reconocido a nivel universal. Esto también lo volvió, como a todos los profetas, un personaje incómodo para los que se veían favorecidos por las relaciones de desigualdad, marginación y represión que imperaron en su tiempo y algunas de las cuales siguen intactas en la actualidad. Para monseñor Gregorio Rosa Chávez, lo que ha cambiado con monseñor Romero son los conceptos de santidad y de martirio, que ahora están ligados a la defensa del pobre, a la opción por ellos, a denunciar las injusticias y a defender la dignidad humana. En honor a la verdad, el modelo de santidad "político" se podría extraer del contenido del Concilio Vaticano II, pero fue monseñor Romero quien lo llevó a la práctica eclesial.

\section{Reto y deuda}

Sin lugar a dudas, el principal reto que tiene en El Salvador la Iglesia que ahora lo reconoce y los que le siguen es ser fiel a monseñor Romero $\mathrm{o}$, mejor, ser fiel a quienes monseñor Romero fue fiel en su vida. En ese sentido, el mayor peligro que debe sortearse es el de descontextualizarlo, desencarnarlo de la realidad que le tocó vivir y convertirlo en un personaje insípido, neutro, incoloro, que pase a formar parte de las imágenes veneradas, pero desprendiéndolo del modelo de santidad del que él es un importante referente.

Precisamente, el rechazo - aunque menos explícito pero innegablemente presente- de algunos sectores sociales y políticos vinculados a los que ordenaron su asesinato y a los que lo celebraron se debe a que no han logrado quitarle ese mordiente de realidad, pese a que ya lo han intentado y lo seguirán intentando, sobre todo fuera de la Iglesia, pero también dentro de ella. 
Las nuevas generaciones deben conocer por vía oficial quiénes fueron los responsables de su martirio y por qué lo asesinaron.
El Salvador tendrá un santo para el mundo, asesinado en su país por salvadoreños y por personajes bautizados en su misma Iglesia, y eso no debe dejarse de lado en esta historia, como también lo pretenden los que quisieran neutralizarlo. La necesidad de que este hecho sea neutro es de quienes lo mataron y aplaudieron el crimen y no de todos los salvadoreños. Son ellos quienes tienen un conflicto con el acto criminal que cometieron. Es increíble que el magnicidio más importante - por su connotación - no haya sido judicializado en el país después de treinta y cinco años de haberse perpetrado, sobre todo habiendo testimonios e investigaciones que señalan a los responsables. En esto también monseñor comparte la suerte de los miles que fueron asesinados siendo inocentes o que fueron desaparecidos durante el conflicto armado. Ninguna grave violación a los derechos humanos ha sido llevada a los tribunales por la Fiscalía General de la República, que tiene el monopolio de la investigación en El Salvador. Las nuevas generaciones deben conocer por vía oficial quiénes fueron los responsables de su martirio y por qué lo asesinaron. Un santo universal sin que en su propio país se reconozca la verdad de su muerte y se le haga justicia será un santo desencarnado de la historia y la realidad a la que respondió. Esta es la materia pendiente en el país. 